\title{
Sphingosine 1-Phosphate Receptor Modulator ONO-4641 Regulates Trafficking of T Lymphocytes and Hematopoietic Stem Cells and Alleviates Immune-Mediated Aplastic Anemia in a Mouse Mode|\$
}

\author{
Takaki Komiya, Masashi Gohda, Hiroki Shioya, and Seishi Katsumata \\ Department of Molecular Physiology, College of Pharmaceutical Sciences, Ritsumeikan University, Kusatsu-shi, Shiga, Japan \\ (H.S); Discovery Research Laboratories, Ono Pharmaceutical Co., Ltd., Mishima-gun, Osaka, Japan (T.K, M.G., H.S., S.K.).
}

Received August 9, 2020; accepted November 23, 2020

\begin{abstract}
ONO-4641 is a second-generation sphingosine 1-phosphate (S1P) receptor modulator that exhibits selectivity for S1P receptors 1 and 5. Treatment with ONO-4641 leads to a reduction in magnetic resonance imaging disease measures in patients with relapsing-remitting multiple sclerosis. The objective of this study was to explore the potential impact of ONO-4641 treatment based on its immunomodulatory effects. Severe aplastic anemia is a bone marrow (BM) failure disease typically caused by aberrant immune destruction of blood progenitors. Although the $\mathrm{T}$ helper type 1-mediated pathology is well described for aplastic anemia, the molecular mechanisms driving disease progression remain undefined. We evaluated the efficacy of ONO-4641 in a mouse model of aplastic anemia. ONO4641 reduced the severity of BM failure in a dose-dependent manner, resulting in higher blood and BM cell counts. By evaluating the mode of action, we found that ONO-4641
\end{abstract}

inhibited the infiltration of donor-derived T lymphocytes to the BM. ONO-4641 also induced the accumulation of hematopoietic stem cells in the BM of model mice. These observations indicate, for the first time, that S1P receptor modulators demonstrate efficacy in the mouse model of aplastic anemia and suggest that treatment with ONO-4641 might delay the progression of aplastic anemia.

\section{SIGNIFICANCE STATEMENT}

ONO-4641 is a second-generation sphingosine 1-phosphate (S1P) receptor modulator selective for S1P receptors 1 and 5 . In this study, we demonstrated that ONO-4641 regulates the trafficking of $\mathrm{T}$ lymphocytes along with hematopoietic stem and progenitor cells, leading to alleviation of pancytopenia and destruction of bone marrow in a bone marrow failure-induced mouse model mimicking human aplastic anemia.

\section{Introduction}

Sphingosine 1- phosphate (S1P), a product of membrane sphingolipid metabolism, is a bioactive lipid involved in the regulation of various cellular processes including cell proliferation, cell migration, actin cytoskeletal reorganization, and cell adhesion (Hla, 2005). There are five known G protein-coupled S1P receptors (S1PR1-S1PR5) that respond to extracellular S1P (Cartier and Hla, 2019). Fingolimod (FTY720) is a first-in-class S1PR-targeted drug approved for the prevention of relapsing forms of multiple sclerosis (MS) (Cohen et al., 2010; Kappos et al., 2010) and has led to the expansion of research and drug development efforts targeting S1PRs. FTY720 is a nonselective S1PR modulator acting

This work received no external funding.

The authors are employees of Ono Pharmaceutical Co., Ltd.

https://doi.org/10.1124/jpet.120.000277.

S This article has supplemental material available at jpet.aspetjournals.org. against four S1PRs (S1PR1, S1PR3, S1PR4, and S1PR5) (Brinkmann et al., 2002). Recently, second-generation S1PR modulators-namely, siponimod (Kappos et al., 2018) and ozanimod (Cohen et al., 2019) — that exhibit a higher degree of selectivity for S1PR1 and S1PR5 have been approved for the treatment of MS. The therapeutic effects of these drugs are considered to be mediated by S1PR1 activation, leading to sustained internalization and desensitization and, in turn, functional suppression of S1PR1 signaling (Oo et al., 2007). In contrast, cardiovascular, hepatic, and respiratory side effects were also observed upon treatment with FTY720 (Meissner and Limmroth, 2016).

ONO-4641 (ceralifimod) is also a second-generation S1PR modulator selective for S1PR1 and S1PR5. S1PR modulators such as FTY720 and ONO-4641 cause the S1PR1 downregulation on lymphocytes, which renders lymphocytes unresponsive to the S1P gradient in secondary lymphoid tissues. As a consequence, S1PR modulators decrease peripheral blood lymphocyte counts by inhibiting egress of lymphocytes

ABBREVIATIONS: BM, bone marrow; CFU, colony forming unit; HSPC, hematopoietic stem and progenitor cell; $\mathrm{LN}$, lymph node; $0.5 \% \mathrm{MC}, 0.5 \mathrm{w} / \mathrm{V}$ $\%$ Methyl Cellulose 400 cP Solution; MS, multiple sclerosis; ONO-4641, 1-(\{6-[(2-methoxy-4-propylbenzyl)oxy]-1-methyl-3,4-dihydronaphthalen-2yl\}methyl)azetidine-3-carboxylic acid; PLT, platelet; RBC, red blood cell; S1P, sphingosine 1-phosphate; S1PR, S1P receptor; TBI, total body irradiation; Th1, T helper type 1; Th17, T helper type 17; WBC, white blood cell. 
from secondary lymphoid tissues (Matloubian et al., 2004; Komiya et al., 2013; Kurata et al., 2017). The phase 2 clinical trial Drug Research Evaluation for MS (DreaMS) study (NCT01081782) demonstrated that ONO-4641 (0.05, 0.1, and $0.15 \mathrm{mg}$ once daily) significantly reduced magnetic resonance imaging disease measures across all doses in patients with relapsing-remitting $\mathrm{MS}$ and reduced the annualized relapse rate by 6 months in patients with MS treated with the 0.1-mg dose (Zipp et al., 2013; Vollmer et al., 2013). The study further demonstrated a dose-dependent lymphocyte count reduction from baseline established at week 2: $40 \%, 60 \%$, and $65 \%$ with the administration of $0.05,0.1$, and $0.15 \mathrm{mg} /$ day, respectively. The efficacy of ONO-4641 was demonstrated in a phase 2 clinical trial for the treatment of MS. As ONO-4641 demonstrated the reduction of lymphocyte infiltration in clinical study in MS, ONO-4641 is also considered to be effective in other lymphocyte-mediated diseases.

Severe aplastic anemia is an acquired BM failure syndrome (Young, 2018). Evidence in the majority of cases suggests that a breakdown in self-tolerance leads to the infiltration of destructive T helper type 1 (Th1) lymphocytes into the BM, where they target hematopoietic stem cells and compromise stromal cells via bystander effects (Chen et al., 2005; Young et al., 2008). As a result, the population of hematopoietic stem and progenitor cells (HSPCs) in the BM is destroyed. Without the ability to replenish platelets and red and white blood cells, patients with aplastic anemia are at an increased risk of bleeding episodes, hypoxia, and infection. If left untreated, aplastic anemia is uniformly fatal (Dezern and Brodsky, 2011).

Although the pathology of aplastic anemia is well defined, the molecular mechanisms that drive disease progression remain to be elucidated. Unlike other autoimmune diseases, such as MS, an inciting self-antigen has not been identified for aplastic anemia. However, mouse models of immunemediated BM failure have been developed successfully by transferring parental splenocytes or lymph node (LN) cells into minor histocompatibility- or major histocompatibilitymismatched recipients, followed by robust immune responses that target BM cells and HSPCs (Bloom et al., 2004; Chen, 2005; Chen et al., 2007). The utility of such aplastic anemia mouse models is well established. Mice exhibit many of the clinical features of aplastic anemia and provide an excellent system for studying the underlying mechanisms of the disease as well as testing the efficacy of potential therapeutics (Bloom et al., 2004; Chen et al., 2007). In such a model, massive lymphocyte infiltration in the BM led to the rapid destruction of HSPCs. It has been demonstrated that S1P acts as a chemoattractant for HSPCs. Their egress from extramedullary tissues depends on S1PR1 (Massberg et al., 2007).

In this study, we evaluated the efficacy of ONO-4641 in a mouse model of aplastic anemia generated by infusing parental LN cells into the irradiated recipient mice. The efficacy of ONO-4641 when combined with cyclosporine, an immunosuppressive drug, was also investigated. ONO-4641 regulates the trafficking of T lymphocytes and HSPCs and alleviates pancytopenia and the destruction of BM in this model. Our results confirm the therapeutic benefits of ONO-4641, implying its potential as a novel therapeutic agent for aplastic anemia.

\section{Materials and Methods}

Chemicals. ONO-4641 (more than 95\% purity as determined by chiral high-performance liquid chromatography) was provided by Ono

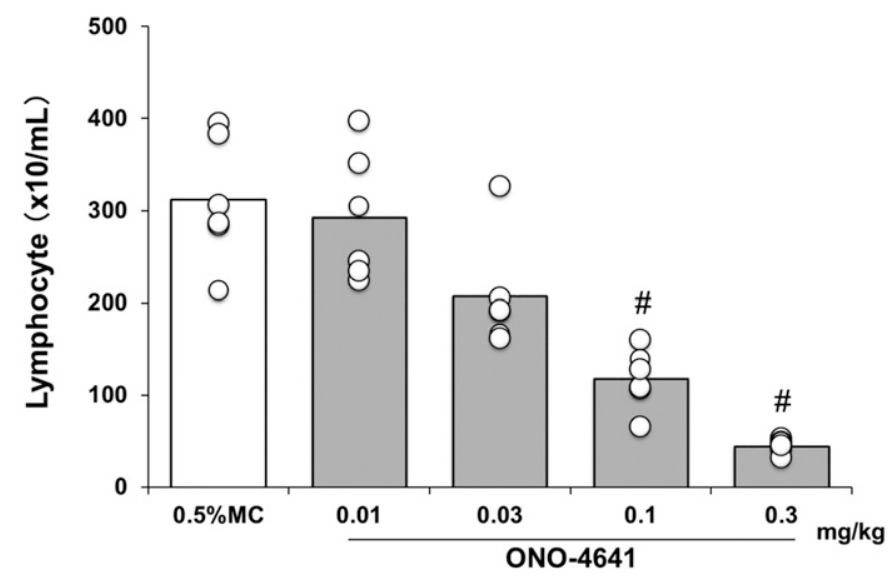

Fig. 1. ONO-4641 decreases peripheral blood lymphocytes. Effect of ONO-4641 (0.01, $0.03,0.1$, or $0.3 \mathrm{mg} / \mathrm{kg})$ on the number of peripheral blood lymphocytes in CBF1 mice 24 hours after the oral administration of a single dose. Data are represented as means and individuals; $n=6$ per group. The $P$ values were determined by Steel's multiple comparison test; ${ }^{\sharp} P<0.05$ vs. $0.5 \% \mathrm{MC}$.

Pharmaceutical Co., Ltd. (Osaka, Japan). Cyclosporine was obtained from Novartis (Switzerland) as Neoral Oral Solution $100 \mathrm{mg} / \mathrm{ml}$. Plerixafor was obtained from Sigma-Aldrich (MO).

Peripheral Blood Lymphocyte Counts in Mice. CBF1 mice were administered a single oral dose of $0.01,0.03,0.1$, or $0.3 \mathrm{mg} / \mathrm{kg}$ of ONO-4641 or $0.5 \mathrm{w} / \mathrm{v} \%$ Methyl Cellulose $400 \mathrm{cP}$ Solution $(0.5 \% \mathrm{MC}$; WAKO, Osaka, Japan) (vehicle). At 24 hours after the administration, blood was collected from the abdominal vena cava of the mice for the measurement of peripheral blood lymphocyte count with an automated hematology analyzer (SF-3000; Sysmex Corporation, Hyogo, Japan).

Experimental Aplastic Anemia Model. Inbred C57BL/6NCr (B6) and hybrid (B6 and BALB/c) F1 (CBF1) mice were obtained from Japan SLC Inc. (Shizuoka, Japan). Male mice 8-10 weeks of age were used in each experiment. Based on national regulations and guidelines, animal experiments were reviewed by the Institutional Animal Care and Use Committee and finally approved by the director of the research institution. The animal experiments were performed in accordance with the regulations for animal experiments of Ono Pharmaceutical Co., Ltd.

CBF1 recipient mice were subjected to 4 Gy total body irradiation (TBI) from an X-ray irradiation device (model MBR-1520R-3; Hitachi Power Solutions, Ibaraki, Japan). BM failure was induced 5-8 hours later by administering $5 \times 10^{6} \mathrm{LN}$ cells with an intravenous injection. The LN cells were harvested from B6 donor mice. Inguinal, brachial, axillary, and mesenteric LNs were obtained for the experiments. In each experiment, mice that received 4 Gy TBI only and TBI + LN cell infusion with $0.5 \% \mathrm{MC}$ administration were used as controls. Mice were bled at 14 days after TBI $+\mathrm{LN}$ cell infusion for peripheral blood lymphocyte counts performed with an automated hematology analyzer and for the measurement of BM cells in femurs with FACSCalibur flow cytometer (BD Biosciences, CA).

ONO-4641 at $0.03,0.1$, or $0.3 \mathrm{mg} / \mathrm{kg}$ was orally administered once a day for 13 days starting from the next day, corresponding to day 1 after TBI + LN cell infusion. In the therapeutic regimen administered after the reduced platelet counts in mice, which corresponds to day 4 after TBI + LN cell infusion, ONO- 4641 at $0.3 \mathrm{mg} / \mathrm{kg}$ was treated daily for 10 days. Cyclosporine at 6 or $30 \mathrm{mg} / \mathrm{kg}$ was administered orally twice a day for 13 days. For the two-drug combination experiment, ONO-4641 $0.1 \mathrm{mg} / \mathrm{kg}$ was administered either alone or in combination with cyclosporine $15 \mathrm{mg} / \mathrm{kg}$ for 13 days starting from day 1 after disease induction. Control mice received equivalent volumes of $0.5 \% \mathrm{MC}$.

Flow Cytometry and Intracellular Cytokine Staining. BM cells were prepared by flushing the femurs with $6 \mathrm{ml}$ PBS. The cells were lysed with ammonium-chloride-potassium (ACK) lysis buffer (Lonza, Basel, Switzerland) to remove red blood cells, followed by washing and suspending in stain buffer (BD Biosciences). The cells 
A

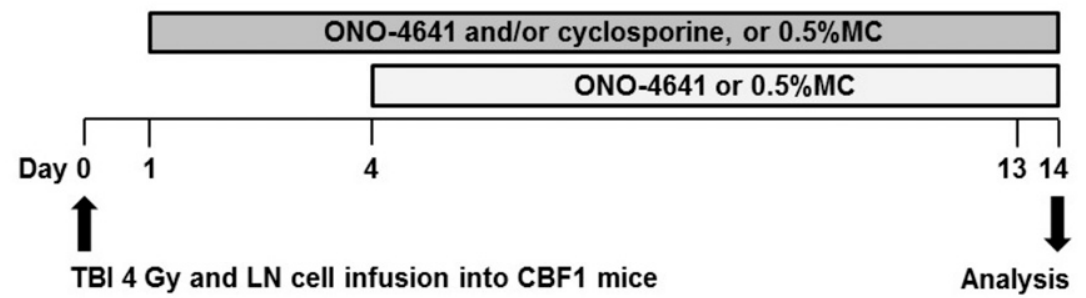

B
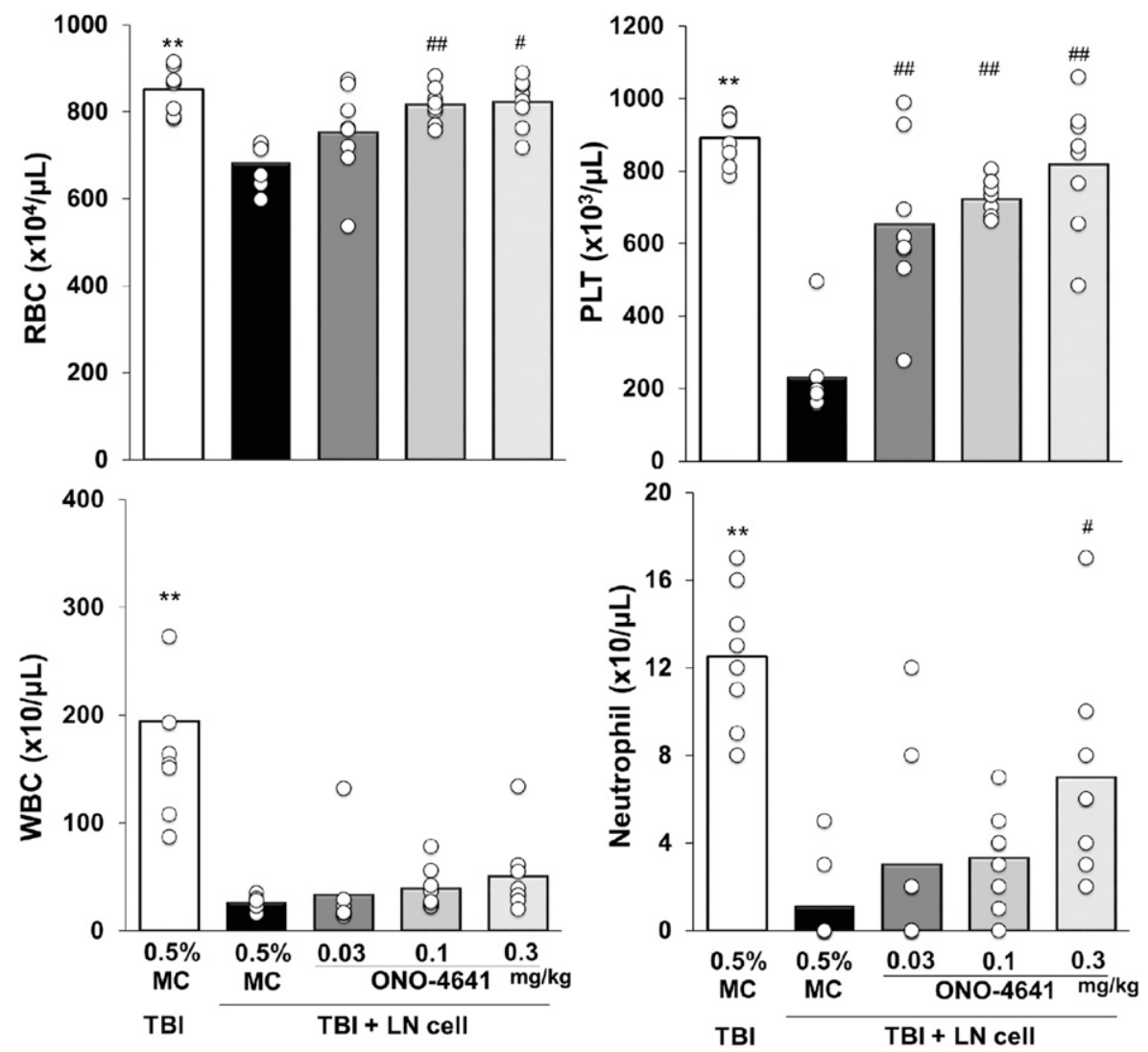

Fig. 2. ONO-4641 and/or cyclosporine treatment alleviates the induction of BM failure in mice. CBF1 mice were subjected to $4 \mathrm{~Gy}$ TBI, and $5 \times 10^{6} \mathrm{LN}$ cells from $\mathrm{B} 6$ mice were administered via caudal vein injection to induce the aplastic anemia model. On day 14 after disease induction, peripheral blood cell count was determined by the hematology analyzer. (A) Schema of the ONO-4641 and/or cyclosporine treatment experiments. (B) CBF1 mice were treated daily with ONO-4641 $(0.03,0.1$, or $0.3 \mathrm{mg} / \mathrm{kg})$ or $0.5 \% \mathrm{MC}$ (vehicle) by oral gavage from day 1 after disease induction. On day 14 after disease induction, peripheral blood cells were determined by a hematology analyzer. Indicated values are presented as means and individuals; $n=8$ per group except for vehicle $(n=7)$. (C) CBF1 mice were treated daily with ONO-4641 $0.3 \mathrm{mg} / \mathrm{kg}$ or $0.5 \%$ $\mathrm{MC}$ (vehicle) by oral gavage from day 4 after disease induction. Indicated values are presented as means and individuals; $n=8$ per group except for vehicle $(n=10)$. (D) In the two-drug combination experiment, $\mathrm{CBF} 1$ mice were treated with either ONO-4641 $0.1 \mathrm{mg} / \mathrm{kg}$, cyclosporine $15 \mathrm{mg} / \mathrm{kg}$ (Cys), $0.5 \% \mathrm{MC}$ alone, or ONO-4641 $0.1 \mathrm{mg} / \mathrm{kg}$ + cyclosporine $15 \mathrm{mg} / \mathrm{kg}$ from day 1 after disease induction. Indicated values are presented as means and individuals; $n=8$ per group except for vehicle $(n=7)$. Steel's multiple comparison test was performed for comparison between the vehicle and the ONO$46410.03,0.1$, and $0.3 \mathrm{mg} / \mathrm{kg}$ groups, with a $P$ value of less than $5 \%$. ${ }^{\#} P<0.05 ;{ }^{\# \#} P<0.01$. Wilcoxon signed-rank sum test was performed for comparison between the vehicle group and the groups receiving TBI only; ONO-4641 0.1, $0.3 \mathrm{mg} / \mathrm{kg}$; cyclosporine $15 \mathrm{mg} / \mathrm{kg}$; or ONO-4641 $0.1 \mathrm{mg} / \mathrm{kg}+$ cyclosporine $15 \mathrm{mg} / \mathrm{kg}$, with a $P$ value of less than $5 \%$. $* P<0.05$; $* * P<0.01$; ***P $P$ 0.001 . Wilcoxon signed-rank sum test was performed for comparison between the ONO-4641 $0.1 \mathrm{mg} / \mathrm{kg}+$ cyclosporine $15 \mathrm{mg} / \mathrm{kg}$ and the ONO$46410.1 \mathrm{mg} / \mathrm{kg}$ or the cyclosporine $15 \mathrm{mg} / \mathrm{kg}$ groups, with a $P$ value of less than $5 \%,+P<0.05$.

Histology. On day 14 after induction, femurs were harvested, fixed in $10 \%$ neutral buffered formalin for 48 hours, decalcified, and preserved in $70 \%$ ethanol at $4^{\circ} \mathrm{C}$ until further use. The femurs were processed, embedded in paraffin, sectioned, and stained with hematoxylin and eosin for histologic examination.

Colony Forming Assay. Femoral BM cells were harvested from mice on day 14 after disease induction for evaluating the number of colony forming units (CFU). BM cells were suspended in methylcellulose medium (MethoCult M03434; Stem Cell Technologies, Vancouver, Canada) containing recombinant IL-3, stem cell factor, and IL-6 but not granulocyte-colony stimulating factor and granulocyte macrophage-colony stimulating factor. BM cells harvested from mice that received TBI only were plated at $2 \times 10^{4}$ cells per milliliter for the determination of granulocyte/macrophage colony forming unit (CFUGM). BM cells from mice that received TBI + LN cell infusion were prepared with the same dilution method as the TBI-only mouse group. Morphologic analysis of colony formation was performed after 12 days of incubation at $37^{\circ} \mathrm{C}$ using an inverted microscope.

HSPC Mobilization in Mice. Male B6 mice were orally administered with $0.3 \mathrm{mg} / \mathrm{kg}$ ONO-4641 or injected subcutaneously with $3 \mathrm{mg} / \mathrm{kg}$ plerixafor daily for 8 days. At 3 hours after the last dosing, were recovered by centrifugation at $400 \mathrm{~g}$ at $4^{\circ} \mathrm{C}$ after each staining/washing step. All samples were analyzed on FACSCalibur flow cytometer. 

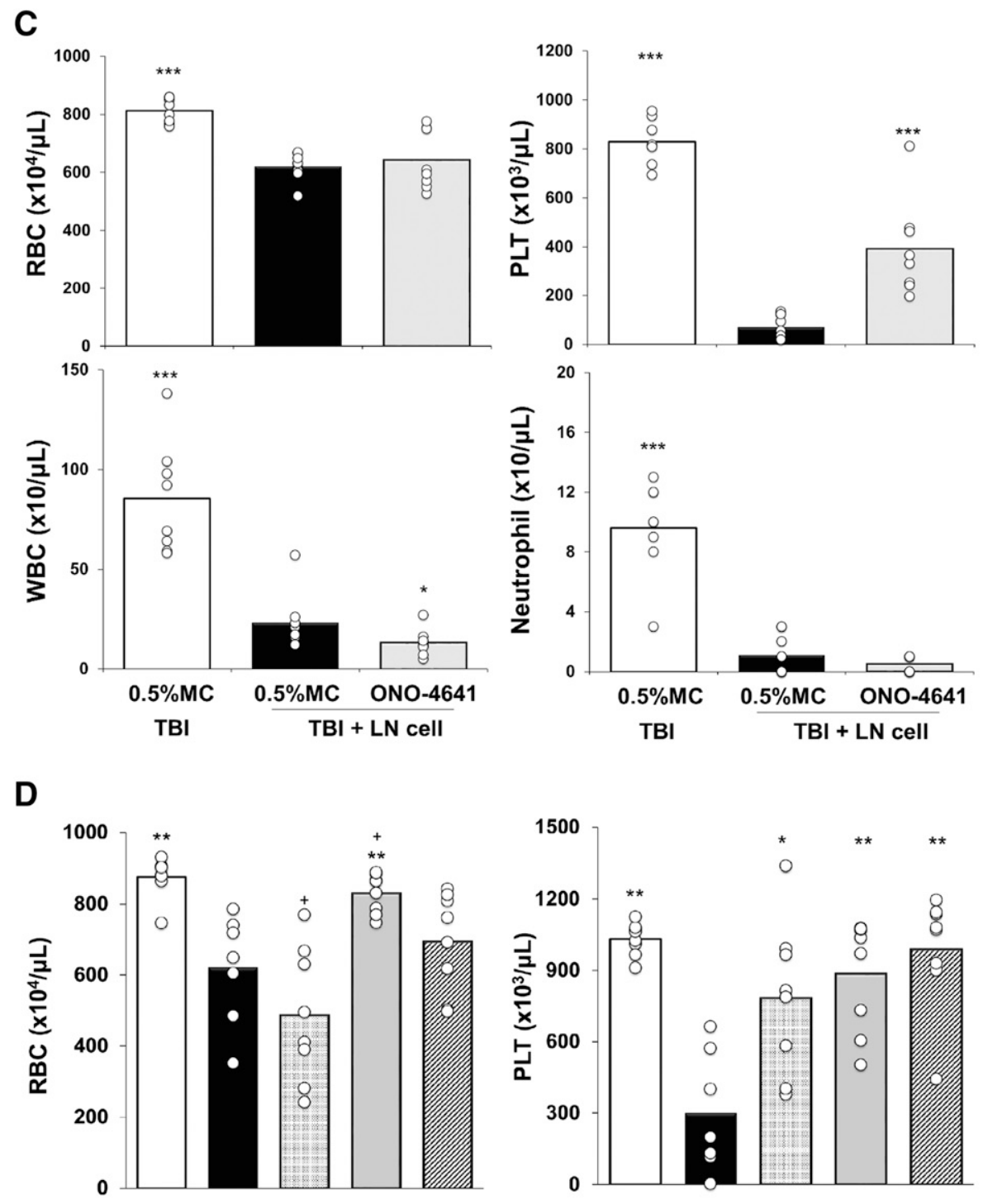

Fig. 2. Continued.
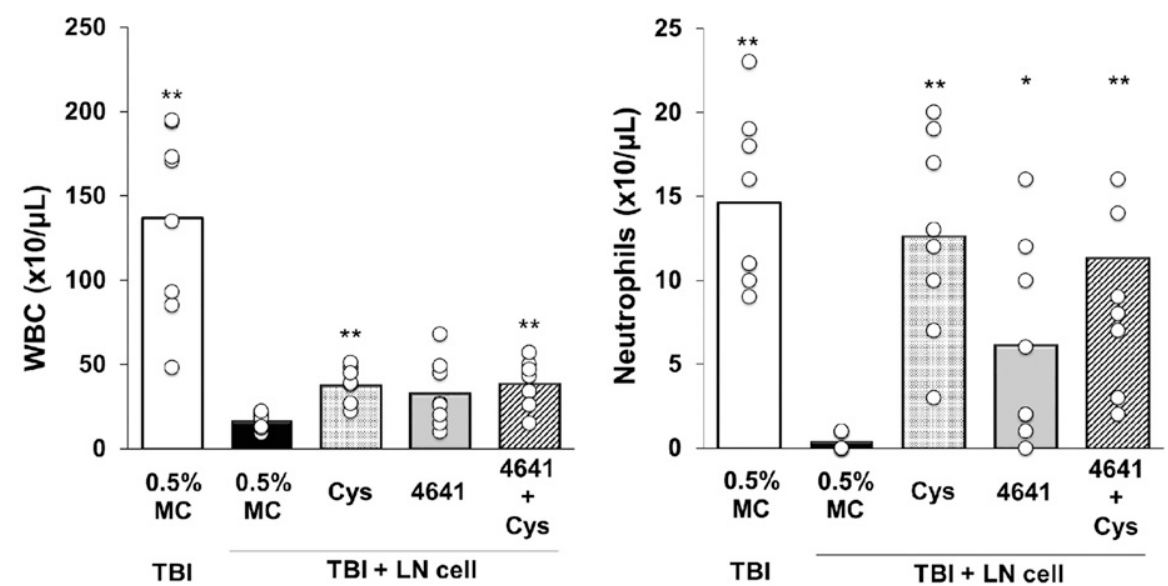

mice were bled for the measurement of HSPCs and BM cells in femurs and of HSPCs in blood with FACSCalibur flow cytometer.

Statistical Analysis. Statistical analysis was performed using SAS System release 9.2 TS2M3 (SAS Institute Japan Inc., Tokyo, Japan) and its cooperative system EXSUS version. 7.7.1 (CAC Croit Corporation, Tokyo, Japan). Statistical significance was determined with Wilcoxon signed-rank sum test in experiments comparing two groups and by Steel's multiple comparison test in experiments

comparing the treatment groups with a control group. A $P$ value of less than $5 \%$ indicated statistical significance.

\section{Results}

Lymphocyte-Reducing Effect of ONO-4641 in CBF1 Mice. ONO-4641 is a selective dual modulator that acts on 
A

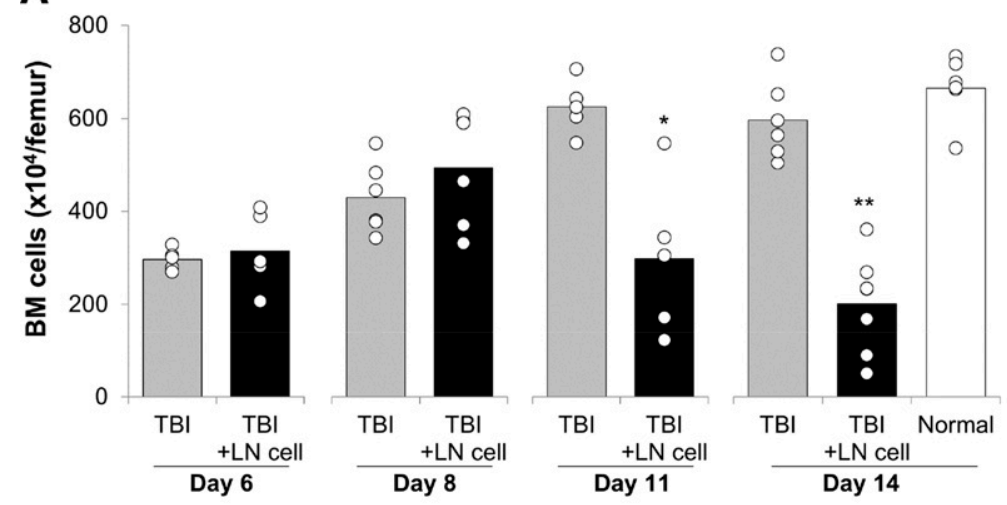

B

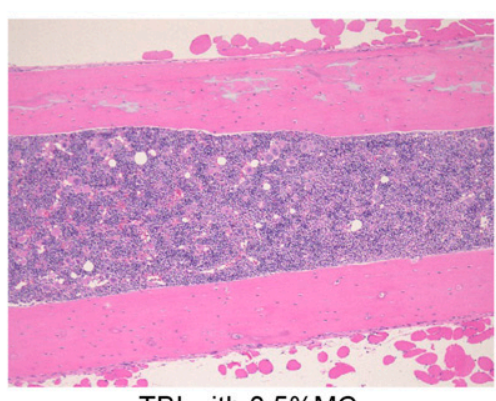

TBI with $0.5 \% \mathrm{MC}$

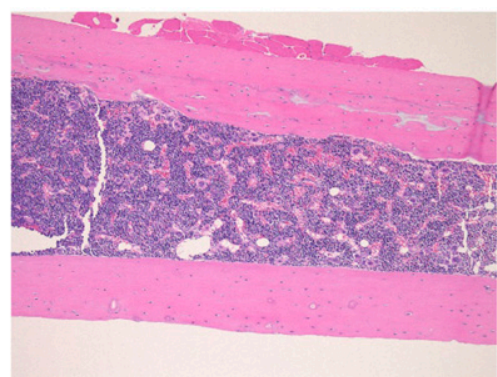

TBI+LN cell with ONO-4641 $0.3 \mathrm{mg} / \mathrm{kg}$

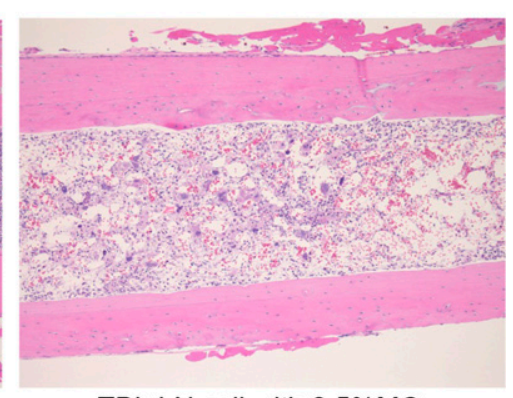

TBI+LN cell with $0.5 \% \mathrm{MC}$
Fig. 3. ONO-4641 treatment reduces the destruction of BM cells by inhibiting the infiltration of donor-derived $\mathrm{T}$ lymphocytes to BM. (A) The counts of total cells in the BM of mice that received TBI only, received TBI + LN cell infusion, or were untreated (normal mice) at the indicated days after disease induction. Indicated values are presented as means and individuals; $n=5$ or 6 per group. (B) Representative hematoxylin and eosin-stained femur section (original magnification, $10 \times$ ) in the treatment groups of TBI only with $0.5 \% \mathrm{MC}$ (vehicle), TBI $+\mathrm{LN}$ cell infusion with vehicle, and TBI + LN cell infusion with ONO-4641 $0.3 \mathrm{mg} / \mathrm{kg}$. (C) Total cell counts in the BM of mice on day 14 . Mice were treated daily with ONO-4641 at $0.03,0.1$, $0.3 \mathrm{mg} / \mathrm{kg}$ or with vehicle by oral gavage starting from day 1 after disease induction. Indicated values are presented as means and individuals; $n=8$ per group except for vehicle $(n=7)$. (D) Representative flow cytometric analysis of IFN- $\gamma$ or IL-17A expressions in donor-derived $\mathrm{CD}^{+}$and $\mathrm{CD}^{+}{ }^{-} \mathrm{T}$ lymphocytes in the groups treated with vehicle or ONO$46410.3 \mathrm{mg} / \mathrm{kg}$ on day 14 . (E) Absolute numbers of donorderived $\mathrm{CD}^{+}$and $\mathrm{CD}^{+}$T-lymphocyte subsets in the groups treated with vehicle or ONO-4641 $0.3 \mathrm{mg} / \mathrm{kg}$ on day 14 . Indicated values are presented as means and individuals; $n=6$ for the vehicle-treated group, and $n=5$ for the group treated with ONO-4641 $0.3 \mathrm{mg} / \mathrm{kg}$. Steel's multiple comparison test was performed for comparison between the vehicle and the ONO-4641 groups, with a $P$ value of less than $5 \%$. ${ }^{\# \#} P<0.01$. Wilcoxon signed-rank sum test was performed for comparison between the TBI-only and the TBI + LN cell infusion with vehicle or the ONO-4641 $0.3 \mathrm{mg} / \mathrm{kg}$ groups, with a $P$ value of less than $5 \%$. $* P<0.05 ; * * P<0.01$.
S1PR1 and S1PR5 and decreases the peripheral blood lymphocyte count in animals by inhibiting lymphocyte egress from secondary lymphoid tissues (Komiya et al., 2013). The lymphocyte-reducing effect by ONO-4641 was observed in patients with multiple sclerosis (Krösser et al., 2015). First, we evaluated the lymphocyte-reducing effect of ONO-4641 in CBF1 mice. At 24 hours after the administration of a single oral dose of $0.01,0.03,0.1$, or $0.3 \mathrm{mg} / \mathrm{kg}$ ONO-4641, the peripheral blood lymphocyte count was decreased by $6 \%, 34 \%, 62 \%$, and $86 \%$ in a dose-dependent manner, respectively (Fig. 1).

Alleviation of Disease Phenotype in Mouse BM Failure Model. The mouse model of immune aplastic anemia was made by infusing major histocompatibility complex-mismatched LN cells from B6 mice into irradiated CBF1 mice (Chen et al., 2005), and the therapeutic effect of ONO-4641 was investigated. The recipient CBF1 mice demonstrated a loss of red blood cells (RBCs), platelets (PLTs), white blood cells (WBCs), and peripheral blood neutrophils on day 14 after 4 Gy TBI and infusion of $5 \times 10^{6} \mathrm{LN}$ cells compared with those in the mice that were subjected to TBI only. Since ONO-4641 significantly decreased the peripheral blood lymphocytes from $0.03 \mathrm{mg} / \mathrm{kg}$ in normal CBF1 mice (Fig. 1), doses of 0.03, 0.1, and $0.3 \mathrm{mg} / \mathrm{kg}$ were employed in this BM failure model. ONO4641 or $0.5 \% \mathrm{MC}$ (vehicle) was administered with daily oral dosing for 13 days starting from the next day, corresponding to day 1 after disease induction (Fig. 2A). We observed that ONO-4641 significantly increased the RBC, PLT, and neutrophil counts in a dose-dependent manner on day 14. In contrast, ONO-4641 did not increase the WBC counts, which may be attributed to its lymphocyte-reducing effect (Fig. 2B). We also tested ONO-4641 at $0.3 \mathrm{mg} / \mathrm{kg}$ in therapeutic regimes, in which treatment started from day 4 after TBI + LN cell infusion when reduced PLT counts were observed. The delayed treatment with ONO-4641 demonstrated significantly higher levels of PLTs but did not increase the levels of RBCs and neutrophils compared with those in the vehicle (Fig. 2C).

Next, we tested the immunosuppressive effect of cyclosporine, a drug widely used in the treatment of acquired aplastic anemia in human and myelodysplastic syndromes. Cyclosporine at 6 or $30 \mathrm{mg} / \mathrm{kg}$ was administered orally twice a day for 13 days after disease induction. Mice that received TBI + LN cell infusion along with cyclosporine demonstrated significantly higher levels of PLTs and neutrophils on day 14. 


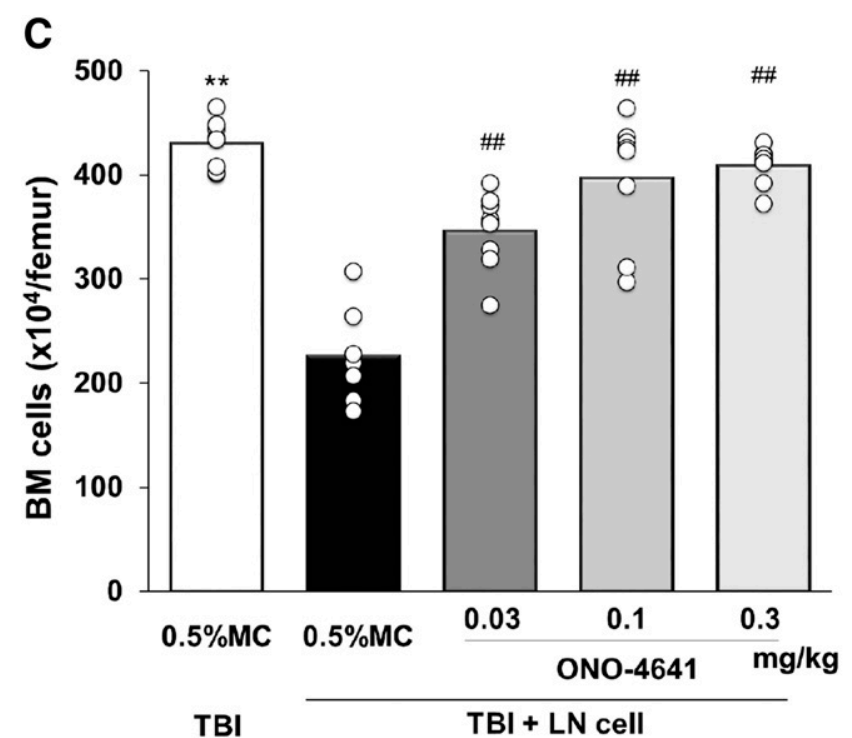

D

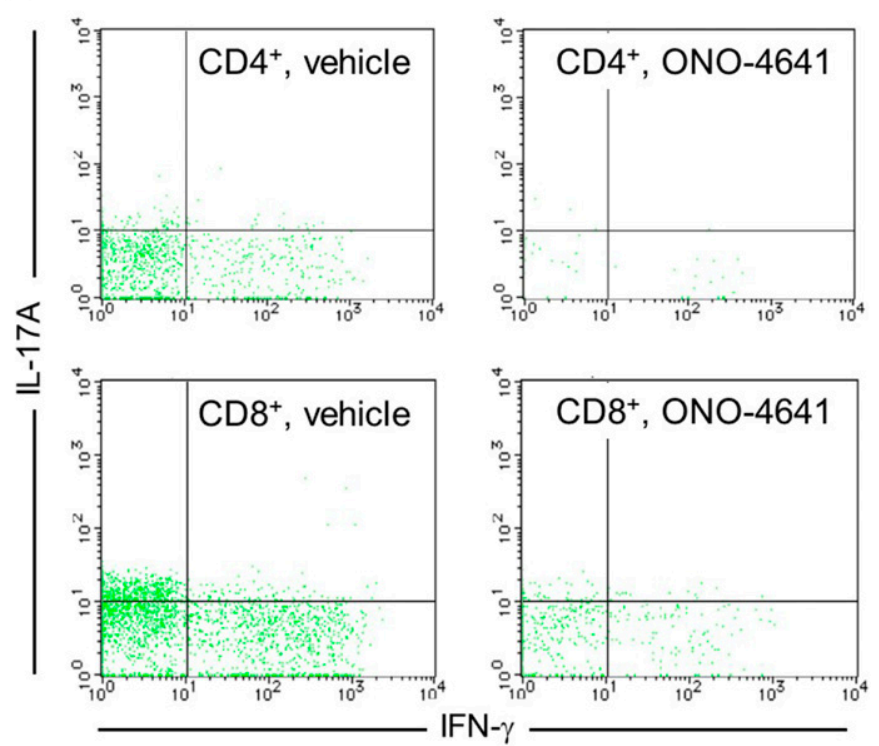

Fig. 3. Continued.

The levels of RBCs in the cyclosporine treatment groups were not different or lower than those in the vehicle group (Supplemental Fig. 1). In addition, mice belonging to the cyclosporine $30 \mathrm{mg} / \mathrm{kg}$ group lost body weight by up to $18 \%$ during the evaluation period, which might be a result of the treatment toxicity. We examined the combinatorial effect of ONO-4641 and cyclosporine by using subtherapeutic doses for both substances. The decrease of RBCs by cyclosporine $15 \mathrm{mg} / \mathrm{kg}$ was recovered by the cotreatment with ONO-4641 $0.1 \mathrm{mg} / \mathrm{kg}$. In addition, ONO-4641 $0.1 \mathrm{mg} / \mathrm{kg}$ combined with cyclosporine $15 \mathrm{mg} / \mathrm{kg}$ demonstrated higher levels of PLTs and neutrophils compared with those treated with vehicle on day 14 (Fig. 2D).

Reduction of BM Hypocellularity by Inhibiting Infiltration of Donor-Derived T Lymphocytes to BM. The severity of pancytopenia induced by TBI + LN cell infusion implicated an immune response that attacked and destroyed
BM cells. The femurs demonstrated a moderate loss of BM cellularity on day 6 in mice that were subjected to TBI only. However, BM cellularity was recovered spontaneously afterward. In contrast, mice that received TBI + LN cells harvested from $\mathrm{B} 6$ mice showed a progressive loss of BM cellularity with numerous empty spots in marrow cavities on day 14 (Fig. 3, A and B). We observed that ONO-4641 treatment increased BM cellularity in mice that received TBI $+\mathrm{LN}$ cell infusion (Fig. 3, $\mathrm{B}$ and $\mathrm{C}$ ).

ONO-4641 has been previously shown to inhibit lymphocyte infiltration into disease lesions by regulating lymphocyte recirculation (Komiya et al., 2013). To understand the mechanism underlying the effect of ONO-4641 in the BM failure model, we attempted to clarify the contribution of different T-lymphocyte populations and activation by analyzing T-lymphocyte markers in the BM. The LN cells from B6 mice $\left(\mathrm{H} 2^{\mathrm{b} / \mathrm{b}}\right)$ were injected into $\mathrm{CBF} 1$ mice $\left(\mathrm{H} 2^{\mathrm{b} / \mathrm{d}}\right)$, utilizing the difference in the H-2Kd haplotype between the donor and recipient mice to identify the transferred $\mathrm{T}$ lymphocytes by flow cytometric analysis. Marked expansion of both donorderived $\mathrm{CD}^{+}$and $\mathrm{CD}^{+}{ }^{+} \mathrm{T}$ lymphocytes was observed in the BM of LN cell-infused mice on day 14. ONO-4641-treated mice demonstrated significantly diminished infiltration of donor-derived $\mathrm{CD} 4^{+}$and $\mathrm{CD} 8^{+} \mathrm{T}$ lymphocytes (Fig. 3D). Next, we analyzed the intracellular IFN- $\gamma$ and IL-17A expressions in $\mathrm{BM} \mathrm{CD} 4^{+} \mathrm{T}$ lymphocytes as representative markers for the Th1 and Th17 immune responses. The number of donorderived $\mathrm{CD}^{+} \mathrm{IFN}^{+} \gamma^{+}$(Th1), $\mathrm{CD}^{+} \mathrm{IL}^{-17 \mathrm{~A}^{+}}$(Th17) lymphocytes, and $\mathrm{CD} 8^{+} \mathrm{T}$ lymphocytes increased in the BM in the vehicle group (Fig. 3D). We observed a decrease of Th1 and Th17 lymphocytes as well as other $\mathrm{CD}^{+}$T-lymphocyte subsets in mice that received ONO-4641 treatment (Fig. 3, D and E). This inhibition of donor-derived T-lymphocyte infiltration may be associated with peripheral blood lymphocytereducing effects by ONO-4641. Taken together, these results suggest that ONO-4641 reduces the destruction of BM cellularity by inhibiting the infiltration of donor-derived $\mathrm{CD} 4^{+}$and $\mathrm{CD8}^{+} \mathrm{T}$ lymphocytes into the BM.

Regulation of Hematopoietic Stem/Progenitor Cell Trafficking after Treatment with ONO-4641. S1PR1 is also expressed on hematopoietic stem cells, and S1P is known to facilitate the egress of HSPCs from the BM into the blood (Massberg et al., 2007). Next, we investigated whether ONO4641 would affect the number of BM HSPCs in this model. Subsequently, we analyzed BM cells for the $\mathrm{Lin}^{-} \mathrm{Sca}-1^{+} \mathrm{c}-\mathrm{Kit}^{+}$ marker phenotype and further divided them into $\mathrm{CD} 34^{+}$and $\mathrm{CD}^{-} 4^{-}$fractions. It was reported that mouse BM Lin ${ }^{-} \mathrm{Sca}-1^{+}$ c-Kit ${ }^{+}$cells consist mostly of HSPCs, whereas BM Lin ${ }^{-} \mathrm{Sca}-1^{+}$

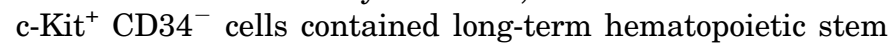
cells (Osawa et al., 1996). The number of both cell populations in the BM was decreased in mice that received TBI + LN cell infusion relative to that in mice that were subjected to TBI only (Fig. 4A). Treatment with ONO-4641 at $0.3 \mathrm{mg} / \mathrm{kg}$ significantly increased the number of both cell populations when compared with treatment with vehicle in the TBI + LN cell and with vehicle in the TBI-only groups (Fig. 4, A and B). To determine the functional role of these changes, we assessed the hematopoietic activity by quantifying the CFU. We found reduction in the number of CFU-GM colonies present in the BM on day 14 in the vehicle-treated TBI + LN cell group relative to that in the TBI-only group. A significant increase was observed in the group treated with ONO-4641 $0.3 \mathrm{mg} / \mathrm{kg}$ 

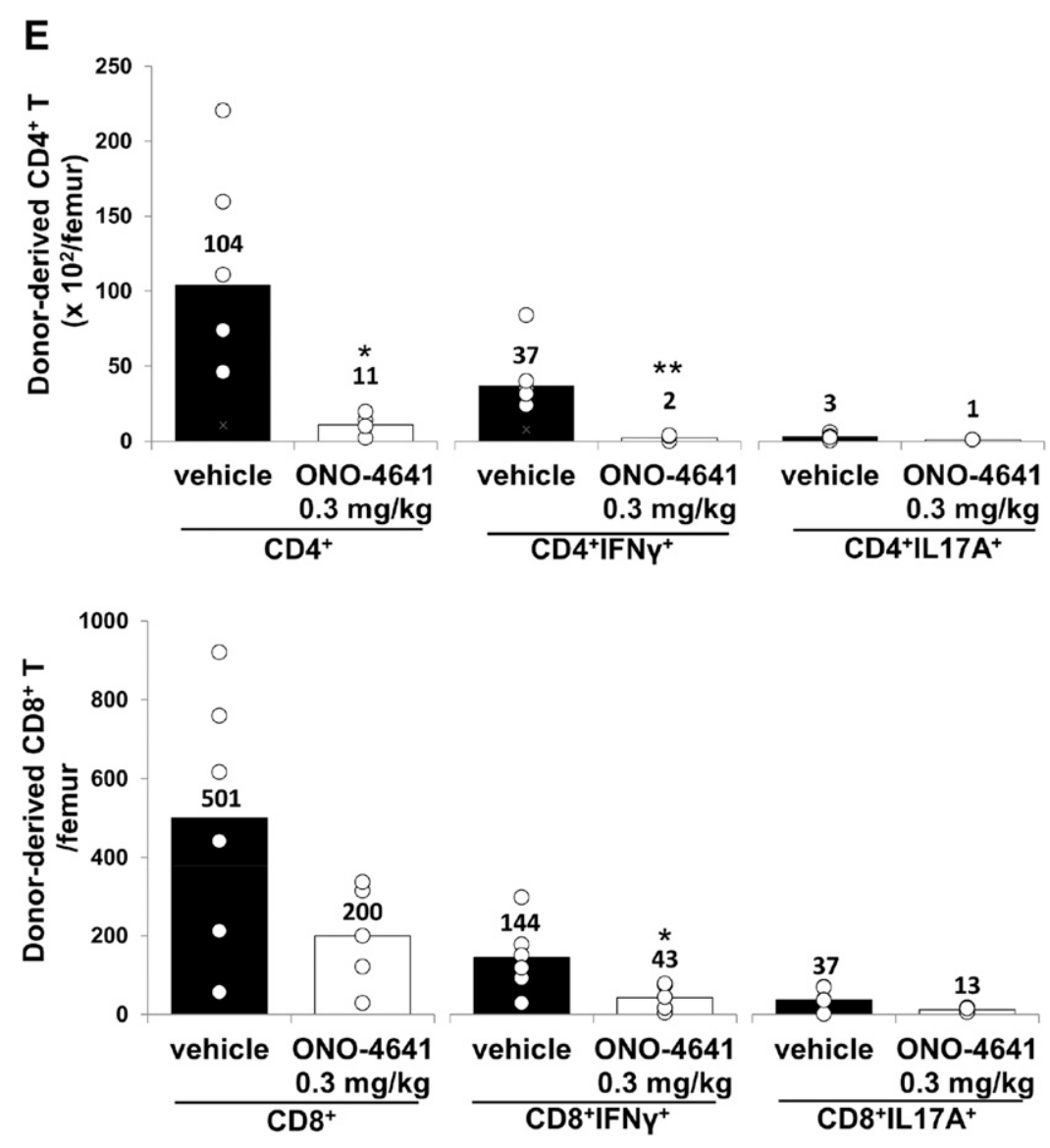

Fig. 3. Continued.

compared with that in the vehicle-treated TBI + LN cell group (Fig. 4C). Collectively, these results indicate that ONO-4641 induces the accumulation of HSPCs in the BM of aplastic anemia model mice.

Regulation of Plerixafor-Induced HSPC Mobilization after Cotreatment with ONO-4641. Plerixafor (AMD3100) is a rapid mobilizing agent that enhances CXCR4-dependent HSPC recruitment to the blood by antagonizing CXCR4, the receptor of SDF-1, in the bone stromal cells (Broxmeyer et al., 2005). The crosstalk between S1P and SDF-1 modulates BM stromal cells and hematopoietic progenitor cell motility (Golan et al., 2012). To further investigate the involvement of ONO-4641 in the regulation of HSPCs, we used a model of plerixafor-induced progenitor cell mobilization. Normal mice were administered ONO-4641 orally or plerixafor subcutaneously once a day for 8 days to evaluate the changes in HSPCs. Notable changes in HSPCs were not observed in the BM with either ONO-4641 or plerixafor treatment, whereas BM cells were decreased with the plerixafor treatment (Fig. 5A). As previously reported (Golan et al., 2012), an increase in the number of HSPCs after plerixafor treatment was detected in the blood. In contrast, the number of HSPCs in the blood was decreased upon treatment with ONO-4641. When mice were treated with both plerixafor and ONO-4641, the HSPC increase in the blood caused by plerixafor was blocked by ONO-4641 (Fig. 5B), suggesting that ONO-4641 interferes with the HSPC mobilization caused by CXCR4-dependent mechanism.

\section{Discussion}

In this study, we characterized the preclinical in vivo effects of ONO-4641 in a mouse model of aplastic anemia. The roles of S1PR modulators that have been demonstrated with the translational mouse models of human diseases have been ascribed to various mechanisms. The primary mechanism is thought to be the drug-induced S1PR1 downregulation on the cell surface. This S1PR1 downregulation, called functional antagonism, causes the reduction of lymphocytes in the peripheral blood by preventing the egress of them from secondary lymphoid tissues (Mandala S, et al., 2002; Schwab SR and Cyster JG, 2007). ONO-4641 is a second-generation S1PR modulator selective for S1PR1 and S1PR5. ONO-4641 also induces S1PR1 downregulation on the cell surface (Komiya et al., 2013). ONO-4641 administration decreased the number of peripheral blood lymphocytes in a dose-dependent manner. The S1PR5 is almost exclusively expressed in the central nervous system, predominantly on oligodendrocytes (Jaillard et al., 2005), suggesting that the S1PR5 modulation of ONO-4641 might not contribute to the efficacy observed in the mouse model of aplastic anemia.

Chen et al. (2005) developed mouse models for immunemediated BM failure by infusion of allogeneic LN cells into irradiated recipients. First, we have demonstrated that the S1PR modulator ONO-4641 alleviated the morbidity of the immune-mediated aplastic anemia mouse model. ONO-4641 treatment starting from the next day after TBI $+\mathrm{LN}$ cell 
A
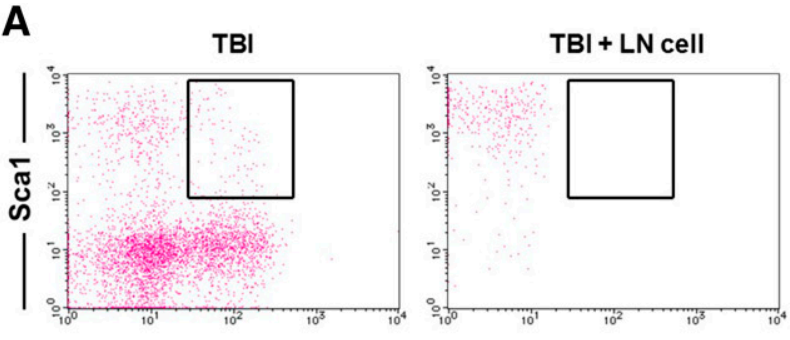

c-Kit
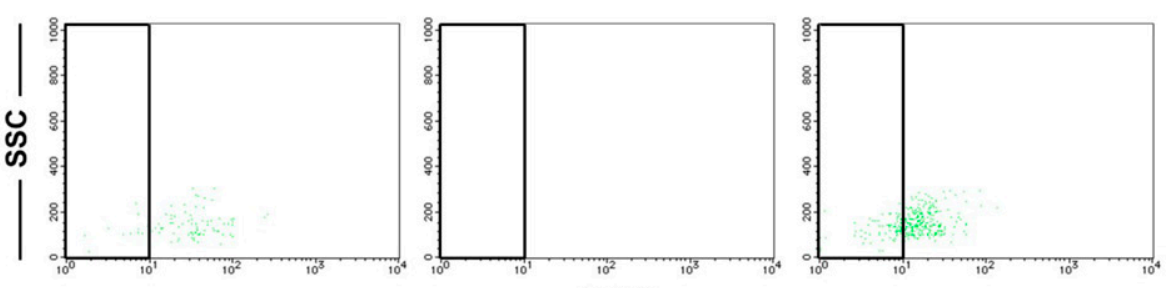

B

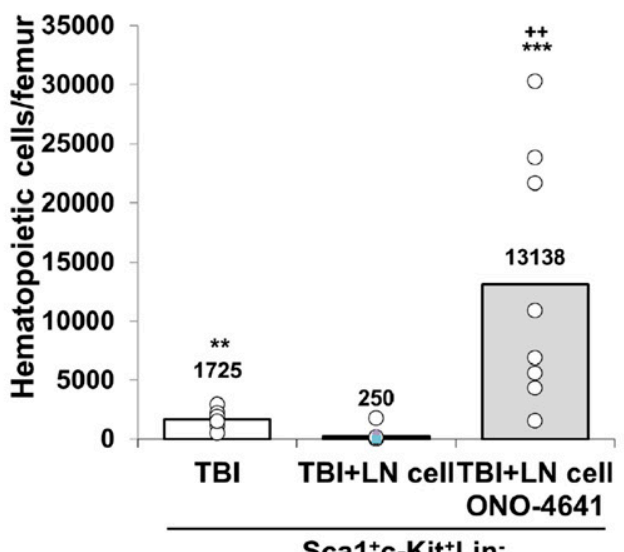

Sca $1^{+} \mathrm{C}-\mathrm{Kit}^{+}{ }^{+}$in $^{-}$



Fig. 4. ONO-4641 treatment increases the number of HSPCs in the BM of model mice. Mice received TBI only with vehicle, TBI + LN cell infusion with $0.5 \% \mathrm{MC}$ (vehicle), or TBI + LN cell infusion with ONO-4641 $0.3 \mathrm{mg} / \mathrm{kg}$ treatment. Mice were treated daily with ONO-4641 $0.3 \mathrm{mg} / \mathrm{kg}$ or vehicle for 13 days starting from day 1 after disease induction. On day 14 , mouse femurs were collected for HSPC analysis. (A) Representative FACS dot plots of HSPCs. Data represent the expressions of Sca-1 and c-Kit on Lin $^{-}$BM cells (top panels) and the expressions of CD34 on $\mathrm{Lin}^{-} \mathrm{Sca}^{+} \mathrm{c}-\mathrm{Kit}^{+} \mathrm{BM}$ cells (bottom panels) of TBI only with vehicle, TBI + LN cell infusion with vehicle, and TBI + LN cell infusion with ONO-4641 $0.3 \mathrm{mg} / \mathrm{kg}$ treatment groups in the femur. (B) The numbers of HSPCs of TBI only with vehicle, TBI + LN cell infusion with vehicle, and TBI + LN cell infusion with ONO$46410.3 \mathrm{mg} / \mathrm{kg}$ treatment groups in the femur. (C) The number of CFU-GM progenitors was enumerated in an in vitro colony forming assay. Indicated values are presented as means and individuals; $n=8$ per group except for vehicle $(n=10)$. Wilcoxon signed-rank sum test was performed for comparison between the TBI + LN cell infusion with vehicle and the TBI only with vehicle or the TBI + LN cell infusion with ONO$46410.3 \mathrm{mg} / \mathrm{kg}$ groups, with a $P$ value of less than $5 \%$.**P $<0.01 ; * * * P<0.001$. Wilcoxon signed-rank sum test was performed for comparison between the TBI-only and the TBI + LN cell infusion with ONO-4641 $0.3 \mathrm{mg} / \mathrm{kg}$ groups, with a $P$ value of less than $5 \% .{ }^{++} P<0.01$; ${ }^{+++} P<0.001$. infusion increased the RBC, PLT, and neutrophil counts in a dose-dependent manner. In contrast, ONO-4641 did not increase the WBC counts, most of which compose the peripheral blood lymphocytes in mice. The ratio of lymphocyte to WBC counts in the vehicle-treated normal mice was $81 \%$, and ONO-4641 at $0.3 \mathrm{mg} / \mathrm{kg}$ decreased the ratio to $43 \%$ by reducing the lymphocytes (Fig. 1). It is assumed that the peripheral blood lymphocyte-reducing effect of ONO-4641 is associated with the minute changes in the WBC counts. Furthermore, the delayed treatment of ONO-4641 from reduced PLT counts, corresponding to day 4 after TBI + LN cell infusion, was still effective. However, it exhibited a lower potency. The delayed treatment with ONO-4641 increased the levels of PLTs but not RBCs and neutrophils compared with that with vehicle. In this therapeutic regimen, however, the number of BM cells was still increased by ONO-4641, suggesting that a longer 
A
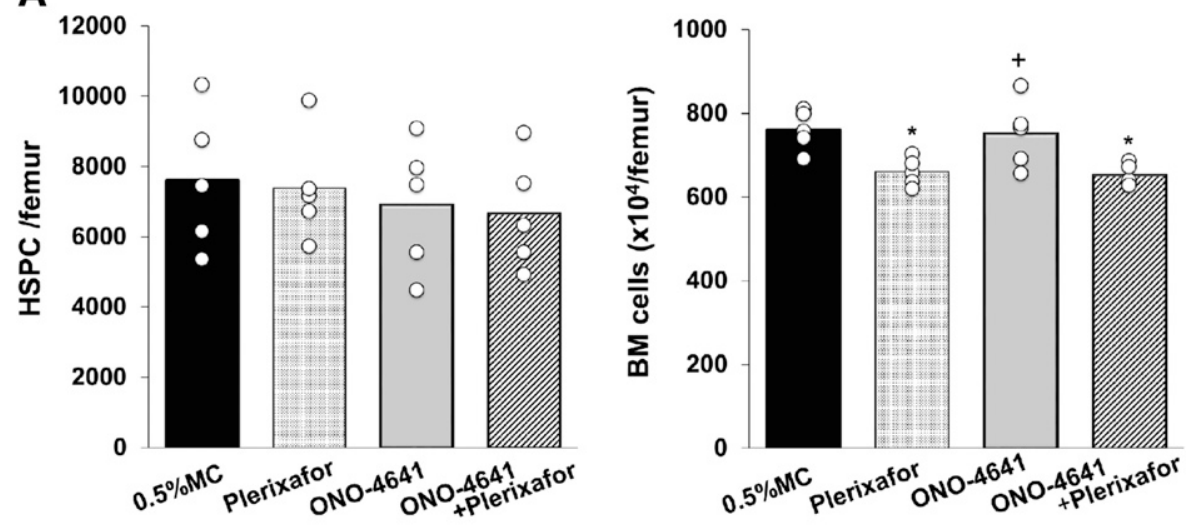

Fig. 5. ONO-4641 regulates plerixafor-induced mobilization of HSPCs in mice. (A) Mice were administered orally with $0.5 \% \mathrm{MC}$ (vehicle) or ONO-4641 $0.3 \mathrm{mg} / \mathrm{kg}$ or injected subcutaneously with PBS, plerixafor $3 \mathrm{mg} / \mathrm{kg}$, or ONO-4641 + plerixafor (oral administration of ONO-4641 30 minutes before subcutaneous injection of plerixafor) for 8 days. At 3 hours after the last dosing, femurs were collected for BM and HSPC cell analysis. Blood was also collected for HSPC cell analysis. (A) The numbers of $\mathrm{Lin}^{-} \mathrm{Sca}^{+}$ c-Kit ${ }^{+}$HSPC and BM cells in the femur. (B) The number of $\mathrm{Lin}^{-} \mathrm{Sca}^{+}{ }^{+} \mathrm{c}-\mathrm{Kit}^{+} \mathrm{HSPCs}$ in the blood. Indicated values are presented as means and individuals; $n=5$ per group. Wilcoxon signedrank sum test was performed for comparison between the vehicle and the ONO-4641 $0.3 \mathrm{mg} / \mathrm{kg}$, the plerixafor $3 \mathrm{mg} / \mathrm{kg}$, or the ONO-4641 + plerixafor groups, with a $P$ value of less than $5 \%$. $* P<0.05$. Wilcoxon signed-rank sum test was performed for comparison between the ONO-4641 + plerixafor and the ONO-4641 $0.3 \mathrm{mg} / \mathrm{kg}$ or the plerixafor $3 \mathrm{mg} / \mathrm{kg}$ groups, with a $P$ value of less than $5 \% .{ }^{+} P<0.05$.

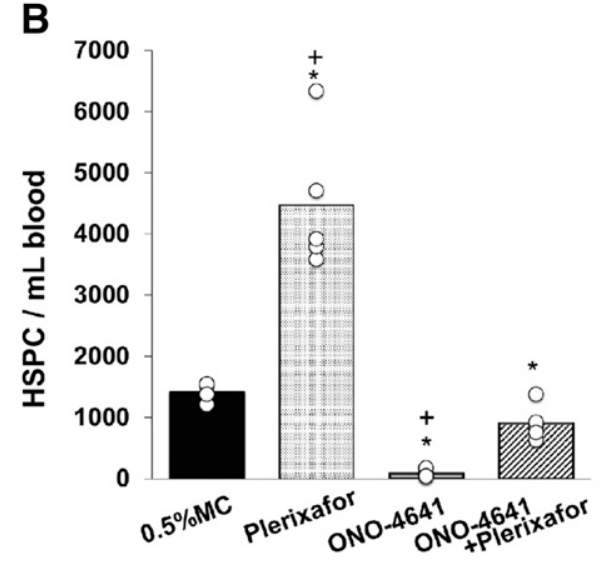

.

treatment period may be needed to recover the levels of RBCs and neutrophils. Cyclosporine is widely used for standard therapy of aplastic anemia with antithymocyte globulin (Peslak et al., 2017). In this mouse model, cyclosporine with a dose of $30 \mathrm{mg} / \mathrm{kg}$ decreased the RBC counts, which might resemble clinically observed side effects such as lytic anemia. We evaluated the efficacy of ONO-4641 when combined with cyclosporine. The combination of a suboptimal dose $(0.1 \mathrm{mg} / \mathrm{kg})$ of ONO-4641 with a suboptimal dose $(15 \mathrm{mg} / \mathrm{kg})$ of cyclosporine resulted in increasing counts of RBC, PLT, and neutrophil compared with those by the treatment with vehicle. This result indicates that individual effects that occur when both lymphocyte trafficking (ONO-4641) and immunologic suppressive (cyclosporine) mechanisms are targeted.

We observed that ONO-4641 significantly alleviated the destruction of BM cells by inhibiting the infiltration of the donor-derived T lymphocytes to the BM. We postulate that the peripheral blood lymphocyte-reducing effect by ONO-4641 involves the inhibition of donor-derived lymphocyte infiltration. In addition, ONO-4641 caused a significant decrease in IFN- $\gamma^{+} \mathrm{CD} 4^{+} \mathrm{T}$ (Th1) and $\mathrm{IL} 17^{+} \mathrm{CD} 4^{+} \mathrm{T}(\mathrm{Th} 17)$ as well as $\mathrm{CD}^{+} \mathrm{T}$ lymphocytes in the BM. Th1 and Th17 immune responses have been reported to play a role in the development of BM failure in aplastic anemia and aplastic anemia mouse models (de Latour et al., 2010), suggesting that the lymphocyte-reducing effect accompanied by the reduction of T-lymphocyte infiltration by ONO-4641 may provide a beneficial effect by preserving BM cellularity in the disease.
Interestingly, our data suggest that treatment with ONO4641 resulted in the accumulation of HSPCs in the BM of aplastic anemia model mice. The egress of HSPCs from extramedullary tissues depends on S1PR1 and HSPCs migrate into the peripheral blood toward higher S1P concentrations (Massberg et al., 2007). The chemokine SDF-1, which is another potent chemoattractant of HSPCs, and its receptor, CXCR4, are key players in HSPC mobilization. In normal mice, the CXCR4 antagonist plerixafor, a drug used to mobilize hematopoietic stem cells to the peripheral blood for collection and subsequent autologous transplantation, induced the mobilization of HSPCs as reported previously (Golan et al., 2012). In contrast, ONO-4641 decreased the HSPC counts in the blood and blocked the plerixafor-induced HSPC mobilization. The data reveal crosstalk between S1P/ S1PR1 and SDF-1/CXCR4 signaling in the HSPC egress and mobilization. ONO-4641 downregulates S1PR1 on the cell surface (Komiya et al., 2013), resulting in unresponsiveness to $\mathrm{S} 1 \mathrm{P}$, thus blocking the egress and the subsequent mobilization of HSPCs. Moreover, in the mouse models, S1P levels in the blood could be lower than that in steady-state conditions, as the number of RBC and PLT, both of which produce S1P, was decreased. Accordingly, mice that received TBI + LN cell infusion treated with ONO-4641 demonstrated a significantly increased number of HSPCs compared with that in the mice that received $\mathrm{TBI}+\mathrm{LN}$ cell infusion treated with vehicle and mice that were subjected to TBI only treated with vehicle. It is noteworthy that ONO-4641 induced the accumulation of HSPCs in the BM, although its potential 
A Pathology in aplastic anemia model

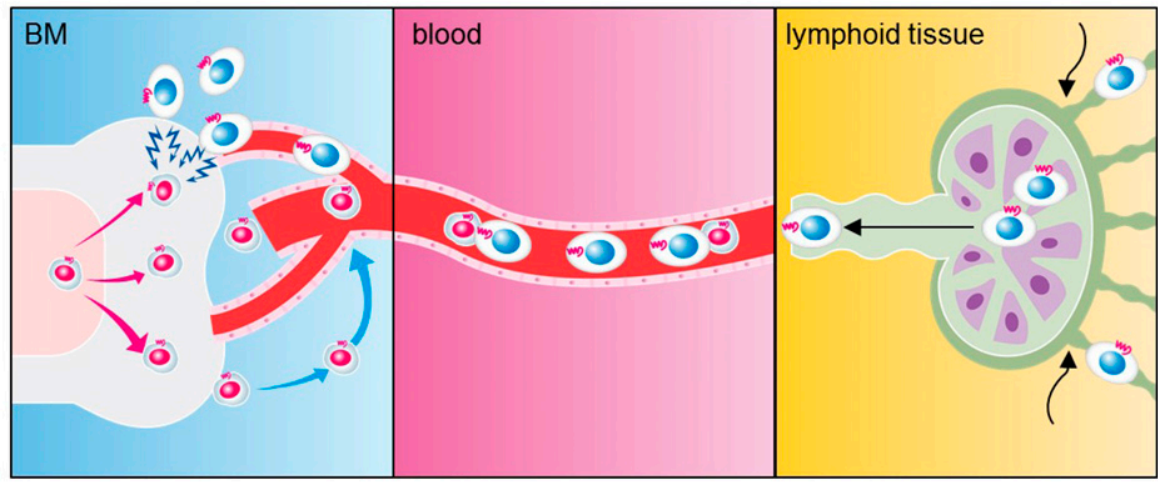

B Treatment with ONO-4641



Fig. 6. Scheme of the proposed mechanistic pathway of ONO-4641 in aplastic anemia model. (A) In the aplastic anemia model, T lymphocytes infiltrate into the BM, where they target and destruct hematopoietic stem cells. (B) ONO-4641 inhibits the infiltration of $\mathrm{T}$ lymphocytes into $\mathrm{BM}$ and the destruction of hematopoietic stem cells by preventing the egress of $\mathrm{T}$ lymphocytes from secondary lymphoid tissues. ONO-4641 also accumulates hematopoietic stem cells in the BM. contribution to overall therapeutic benefits provided by ONO-4641 remains unclear.

In conclusion, we have demonstrated that ONO-4641 alleviated pancytopenia and the destruction of BM by inhibiting the infiltration of donor-derived $\mathrm{T}$ lymphocytes and accumulated hematopoietic stem cells in the BM (Fig. 6). The S1PR modulators might be promising targets for strategies aimed at ameliorating the progression of aplastic anemia.

\section{Acknowledgments}

The authors would like to thank Yosuke Kaneko for critical review of the manuscript.

\section{Authorship Contributions}

Participated in research design: Komiya, Gohda, Katsumata.

Conducted experiments: Komiya, Gohda, Shioya.

Performed data analysis: Komiya, Shioya.

Wrote or contributed to the writing of the manuscript: Komiya, Shioya.

\section{References}

Bloom ML, Wolk AG, Simon-Stoos KL, Bard JS, Chen J, and Young NS (2004) A mouse model of lymphocyte infusion-induced bone marrow failure. Exp Hematol 32:1163-1172.

Brinkmann V, Davis MD, Heise CE, Albert R, Cottens S, Hof R, Bruns C, Prieschl E, Baumruker T, Hiestand P, et al. (2002) The immune modulator FTY720 targets sphingosine 1-phosphate receptors. J Biol Chem 277:21453-21457.

Broxmeyer HE, Orschell CM, Clapp DW, Hangoc G, Cooper S, Plett PA, Liles WC, Li X, Graham-Evans B, Campbell TB, et al. (2005) Rapid mobilization of murine and human hematopoietic stem and progenitor cells with AMD3100, a CXCR4 antagonist. J Exp Med 201:1307-1318.
Cartier A and Hla T (2019) Sphingosine 1-phosphate: lipid signaling in pathology and therapy. Science 366:eaar5551.

Chen J (2005) Animal models for acquired bone marrow failure syndromes. Clin Med Res 3:102-108.

Chen J, Brandt JS, Ellison FM, Calado RT, and Young NS (2005) Defective stromal cell function in a mouse model of infusion-induced bone marrow failure. Exp Hematol 33:901-908.

Chen J, Ellison FM, Eckhaus MA, Smith AL, Keyvanfar K, Calado RT, and Young NS (2007) Minor antigen h60-mediated aplastic anemia is ameliorated by immunosuppression and the infusion of regulatory $\mathrm{T}$ cells. J Immunol 178:4159-4168.

Cohen JA, Barkhof F, Comi G, Hartung HP, Khatri BO, Montalban X, Pelletier J, Capra R, Gallo P, Izquierdo G, et al.; TRANSFORMS Study Group (2010) Oral fingolimod or intramuscular interferon for relapsing multiple sclerosis. $N$ Engl $J$ Med 362:402-415.

Cohen JA, Comi G, Selmaj KW, Bar-Or A, Arnold DL, Steinman L, Hartung HP, Montalban X, Kubala Havrdová E, Cree BAC, et al.; RADIANCE Trial Investigators (2019) Safety and efficacy of ozanimod versus interferon beta-1a in relapsing multiple sclerosis (RADIANCE): a multicentre, randomised, 24-month, phase 3 trial. Lancet Neurol 18:1021-1033.

Dezern AE and Brodsky RA (2011) Clinical management of aplastic anemia. Expert Rev Hematol 4:221-230.

de Latour RP, Visconte V, Takaku T, Wu C, Erie AJ, Sarcon AK, Desierto MJ, Scheinberg P, Keyvanfar K, Nunez O, et al. (2010) Th17 immune responses contribute to the pathophysiology of aplastic anemia. Blood 116:4175-4184.

Golan K, Vagima Y, Ludin A, Itkin T, Cohen-Gur S, Kalinkovich A, Kollet O, Kim C, Schajnovitz A, Ovadya Y, et al. (2012) S1P promotes murine progenitor cell egress and mobilization via S1P1-mediated ROS signaling and SDF-1 release. Blood 119: $2478-2488$.

Hla T (2005) Genomic insights into mediator lipidomics. Prostaglandins Other Lipid Mediat 77:197-209.

Jaillard C, Harrison S, Stankoff B, Aigrot MS, Calver AR, Duddy G, Walsh FS, Pangalos MN, Arimura N, Kaibuchi K, et al. (2005) Edg8/S1P5: an oligodendroglial receptor with dual function on process retraction and cell survival. J Neurosci 25: 1459-1469.

Kappos L, Bar-Or A, Cree BAC, Fox RJ, Giovannoni G, Gold R, Vermersch P, Arnold DL, Arnould S, Scherz T, et al.; EXPAND Clinical Investigators (2018) Siponimod versus placebo in secondary progressive multiple sclerosis (EXPAND): a doubleblind, randomised, phase 3 study. Lancet 391:1263-1273. 
Kappos L, Radue EW, O'Connor P, Polman C, Hohlfeld R, Calabresi P, Selmaj K, Agoropoulou C, Leyk M, Zhang-Auberson L, et al.; FREEDOMS Study Group (2010) A placebo-controlled trial of oral fingolimod in relapsing multiple sclerosis. $N$ Engl J Med 362:387-401.

Komiya T, Sato K, Shioya H, Inagaki Y, Hagiya H, Kozaki R, Imai M, Takada Y, Maeda T, Kurata H, et al. (2013) Efficacy and immunomodulatory actions of ONO4641, a novel selective agonist for sphingosine 1-phosphate receptors 1 and 5, in preclinical models of multiple sclerosis. Clin Exp Immunol 171:54-62.

Krösser S, Wolna P, Fischer TZ, Boschert U, Stoltz R, Zhou M, and Darpo B (2015) Effect of ceralifimod (ONO-4641) on lymphocytes and cardiac function: randomized, double-blind, placebo-controlled trial with an open-label fingolimod arm J Clin Pharmacol 55:1051-1060.

Kurata H, Kusumi K, Otsuki K, Suzuki R, Kurono M, Komiya T, Hagiya H, Mizuno H, Shioya H, Ono T, et al. (2017) Discovery of a 1-methyl-3,4-dihydronaphthalene-based sphingosine-1-phosphate (S1P) receptor agonist ceralifimod (ONO-4641). A S1P 1 and $\mathrm{S}_{1} \mathrm{P}_{5}$ selective agonist for the treatment of autoimmune diseases. $J$ Med Chem 60:9508-9530.

Mandala S, Hajdu R, Bergstrom J, Quackenbush E, Xie J, Milligan J, Thornton R, Shei GJ, Card D, Keohane C, et al. (2002) Alteration of lymphocyte trafficking by sphingosine-1-phosphate receptor agonists. Science 296:346-349.

Massberg S, Schaerli P, Knezevic-Maramica I, Köllnberger M, Tubo N, Moseman EA, Huff IV, Junt T, Wagers AJ, Mazo IB, et al. (2007) Immunosurveillance by hematopoietic progenitor cells trafficking through blood, lymph, and peripheral tissues. Cell 131:994-1008.

Matloubian M, Lo CG, Cinamon G, Lesneski MJ, Xu Y, Brinkmann V, Allende ML, Proia RL, and Cyster JG (2004) Lymphocyte egress from thymus and peripheral lymphoid organs is dependent on S1P receptor 1. Nature 427:355-360.

Meissner A and Limmroth V (2016) Update on the cardiovascular profile of fingolimod in the therapy of relapsing-remitting multiple sclerosis (MS). Mult Scler Relat Disord 8:19-26.
Oo ML, Thangada S, Wu MT, Liu CH, Macdonald TL, Lynch KR, Lin CY, and Hla T (2007) Immunosuppressive and anti-angiogenic sphingosine 1-phosphate receptor1 agonists induce ubiquitinylation and proteasomal degradation of the receptor. $J$ Biol Chem 282:9082-9089.

Osawa M, Hanada K, Hamada H, and Nakauchi H (1996) Long-term lymphohematopoietic reconstitution by a single CD34-low/negative hematopoietic stem cell. Science 273:242-245.

Peslak SA, Olson T, and Babushok DV (2017) Diagnosis and treatment of aplastic anemia. Curr Treat Options Oncol 18:70.

Schwab SR and Cyster JG (2007) Finding a way out: lymphocyte egress from lymphoid organs. Nat Immunol 8:1295-1301.

Vollmer T, Zipp F, Bar-Or A, Due B, Thangavelu K, Fischer TZ, and Selmaj K (2013) Magnetic resonance imaging measures of efficacy in patients with multiple sclerosis receiving ONO-4641, a sphingosine-1-phosphate receptor-1 and -5 agonist: interim results from an extension of the DreaMS study. Mult Scler J 19: $226-227$.

Young NS (2018) Aplastic anemia. N Engl J Med 379:1643-1656.

Young NS, Scheinberg P, and Calado RT (2008) Aplastic anemia. Curr Opin Hematol 15:162-168.

Zipp F, Vollmer T, Bar-Or A, Due B, Thangavelu K, Fischer TZ, and Selmaj K (2013) Relapse rates in patients with multiple sclerosis receiving ONO-4641, a sphingosine-1-phosphate receptor-1 and -5 agonist: interim results from an extension of the DreaMS study. Mult Scler J 19:454-455.

Address correspondence to: Takaki Komiya, Discovery Research Laboratories, Ono Pharmaceutical Co., Ltd., 3-1-1 Sakurai, Shimamoto-cho, Mishimagun, Osaka, 618-8585, Japan. E-mail: t.komiya@ono.co.jp 